\title{
Aspectos teórico-metodológicos do processo comunicativo de deliberação online
}

Os espaços da rede destinados à discussão são majoritariamente utilizados para a prática da conversação informal, para trocar opiniões, esclarecer entendimentos sobre questões de interesse comum e para reafirmar discursos e quadros simbólicos compartilhados responsáveis pela união de grupos e indivíduos que se sentem vinculados por determinadas afinidades (Doury e Marcoccia, 2007; Witschge, 2004). Na web (e também fora dela), os cidadãos conversam a respeito de seus interesses e necessidades, desenvolvendo assim não só laços afetivos de empatia e proximidade, mas também retomando e reformulando constantemente códigos de pertencimento e união. A conversação informal é marcada, em um primeiro momento, pelo prazer de estar junto, de compartilhar com o outro as experiências vividas, sem a preocupação de atingir metas e objetivos a curto ou longo prazo (Marques, 2010). No entanto, acredito que não se pode isolar em pólos opostos formas de sociabilidade voltadas, de um lado, para o jogo lúdico da socialização e, de outro, para a argumentação sobre questões de interesse coletivo e sobre normas que regem as estruturas institucionalizadas dos vínculos entre os indivíduos.

No intuito de refletir sobre a necessidade de construírmos uma proposta teórico-metodológica para a análise qualitativa de processos de troca argumentativa online que combine as especificidades das interações sociais rotineiras da rede com o caráter reflexivo das interações politizadas, este texto encontra-se dividido em quatro partes. Na primeira parte, defino o conceito de deliberação, salientando suas dimensões processuais e comunicativas. Na segunda parte, 
apresento algumas das características das esferas públicas constituídas online e seu potencial para a formação de processos deliberativos. A terceira parte é dedicada à apresentação dos principais critérios normativos da deliberação a serem adaptados e operacionalizados no estudo das trocas políticas de argumentos em rede, seja em espaços explicitamente destinados à discussão política ou não. Finalmente, a partir da análise de alguns modelos de investigação empírica da deliberação online existentes, busco elaborar uma proposta metodológica de estudo ampla o suficiente para ser adequada a desenhos de pesquisa específicos.

\section{A deliberação como processo comunicativo}

De maneira geral, os estudos sobre a noção de deliberação pública têm sua base conceitual marcada pelos trabalhos do filósofo alemão Jürgen Habermas (1997; 2005; 2006), que o associa aos conceitos de esfera pública, ética do discurso e opinião pública. Uma esfera pública surge a partir do momento em que vários indivíduos e grupos consideram que uma questão merece ser discutida de maneira coletiva, de modo a buscar um entendimento recíproco do problema em causa. Nesse sentido, a esfera pública apresenta-se para Habermas como "uma rede adequada para a comunicação de conteúdos, tomadas de posição e opiniões, nela os fluxos comunicacionais são filtrados e sintetizados a ponto de se condensarem em opiniões públicas enfeixadas em temas específicos." (Habermas, 1997, p. 92). Segundo ele, a deliberação toma forma em uma "rede de discursos e negociações" (Habermas, 1997, p. 47) na qual se pode discutir racionalmente acerca de problemas práticos, coletivos e individuais. É importante destacar o uso que Habermas faz da palavra "rede" para definir tanto a esfera pública, quanto o processo deliberativo, pois isso define a deliberação como o entrecruzamento de debates formais e informais que se estabelecem em "uma pluralidade de esferas autônomas, dispersas e comunicativamente articuladas” (Dean, 2003, p. 103).

A deliberação não se restringe a uma troca discursiva de argumentos racionais ou a um único momento de discussões quando as decisões são tomadas. Para além disso, ela é, sobretudo, um processo social de comunicação através do qual os indivíduos têm, em uma perspectiva ideal, a oportunidade de se constituírem como interlocutores, apresentando seus pontos de vista e suas perspectivas diante dos outros, interpelando-os e demandando-lhes a validação de seus argumentos após uma discussão baseada no respeito recíproco. Sob esse viés, a deliberação pode ser compreendida como uma atividade discursiva capaz de conectar as esferas comunicativas formais e 
informais nas quais diferentes atores e discursos estabelecem um diálogo que tem por principal objetivo a avaliação e a compreensão de um problema coletivo ou de uma questão de interesses geral. A prática de intercompreensão exigida pela deliberação demanda um movimento em direção ao outro. Tal movimento valoriza tanto as dimensões afetivas do "estar junto com", quanto as capacidades reflexivas do uso da linguagem, ou seja, o esforço de considerar a palavra do outro, de reconhecê-lo como potencial interlocutor, de convencê-lo e de se deixar persuadir por ele.

A deliberação requer que os indivíduos sejam capazes de dialogar através de suas diferenças, sem colocá-las entre parênteses. E, justamente por isso, ela envolve também o dissenso e o pluralismo agonístico (Mouffe, 1999). O engajamento na deliberação requer, de acordo com o ideal habermasiano, que todos os participantes sejam capazes de formular razões próprias e passíveis de serem compreendidas e aceitas; de iniciar debates e interpretar suas necessidades de maneira reflexiva, expondo seus interesses sob uma perspectiva generalizante, sem que haja desigualdades de acesso e de poder. Os participantes da deliberação devem negociar as regras e os princípios normativos, os quais são responsáveis por definir, ao mesmo tempo, a natureza do vínculo existente entre eles e a dinâmica de suas trocas argumentativas. Podemos mencionar, segundo Habermas (1997), especialmente os seguintes princípios:

Tabela 1 - Princípios normativos centrais de definição das trocas argumentativas na esfera pública

\begin{tabular}{|c|c|}
\hline Princípio & Características \\
\hline $\begin{array}{l}\text { Racionalidade (expres- } \\
\text { são racional da opinião) }\end{array}$ & $\begin{array}{l}\text { Os pontos de vista devem ser construídos sob a forma de argumentos potencialmente } \\
\text { aceitáveis por todos e capazes de ser desafiados e justificados. }\end{array}$ \\
\hline $\begin{array}{l}\text { Paridade de status, } \\
\text { igualdade discursiva }\end{array}$ & $\begin{array}{l}\text { Não deve existir coerções ligadas ao poder e ao dinheiro nas deliberações. } \\
\text { Prevalece não o mais forte ou mais rico, mas o melhor argumento. } \\
\text { Capacidades necessárias para se engajar na discussão como parceiro. }\end{array}$ \\
\hline $\begin{array}{l}\text { Transparência } \\
\text { e publicidade }\end{array}$ & $\begin{array}{l}\text { Argumentos, regras e premissas que sustentam pontos } \\
\text { de vista devem ser acessíveis a todos. }\end{array}$ \\
\hline Inclusividade & $\begin{array}{l}\text { Todos os indivíduos direta ou indiretamente concernidos devem poder participar } \\
\text { e devem ser vistos como tendo algo a contribuir para o debate. }\end{array}$ \\
\hline Reciprocidade & $\begin{array}{l}\text { Os parceiros de interação devem ter a capacidade de adotar o ponto de vista } \\
\text { do outro e responder-lhe. Eles devem ouvir e reagir aos comentários } \\
\text { formulados por outros participantes. }\end{array}$ \\
\hline Reflexividade & $\begin{array}{l}\text { Os participantes devem examinar criticamente seus valores, pressupostos } \\
\text { e interesses diante de comentários e críticas feitas pelos outros. }\end{array}$ \\
\hline
\end{tabular}

Fonte: elaborada pela autora. 
Alguns desses princípios, como veremos mais adiante, são utilizados como base da operacionalização dos critérios que permitem identificar e avaliar a deliberação online.

\section{Esferas públicas e deliberação online}

É possível perceber, em diferentes espaços da rede, uma dinâmica de negociação e contestação de pontos de vista em busca de um entendimento partilhado de determinadas questões (Dean, 2003). Contudo, não se pode afirmar que a presença de diferentes públicos e perspectivas em espaços discursivos online transformam, automaticamente, a internet em uma esfera pública (Papacharissi, 2002). Em primeiro lugar, não se pode esquecer que a natureza das trocas que constituem uma esfera pública é de natureza conflitiva, nas quais o dissenso não é sinônimo de desconhecimento ou desconsideração do outro e de sua perspectiva, mas revela que, a partir de uma reflexão sobre o ponto de vista do outro e, mesmo não concordando com ele, os interlocutores se dispõem a dar continuidade ao diálogo. Em segundo lugar, não se pode pressupor a existência online de um público ou de uma comunidade argumentativa que partilha a mesma base de pressupostos e valores desde o início de uma conversação, como se esse público já estivesse "de acordo" de antemão.

A cautela em apontar espaços online como esferas públicas deriva do fato de que os diferentes tipos de arquitetura discursiva dos espaços online possuem tanto o potencial de constranger quanto de facilitar a abertura, o uso da razão, a criatividade cultural, a auto-organização e a solidariedade. Desse modo, é extremamente necessário levar em conta o potencial da arquitetura das redes para a sociabilidade, a produção de conflito e a contestação pública de pontos de vista e argumentos. Torna-se assim muito mais proveitoso pensar que, em vez de simplesmente entrar em uma esfera pública existente, a internet se transforma em uma esfera pública somente quando uma diversidade de indivíduos e públicos se engajam em uma atividade reflexiva, conflitual e cooperativa (Bohman, 2004; Witschge, 2004).

Todavia, a proliferação e a diversidade de públicos e vozes no ciberespaço podem acarretar alguns problemas. Habermas (2006) destaca, por exemplo, que a formação de uma multitude de miniespaços públicos especializados na web poderia levar a uma fragmentação maior dos públicos que, reunidos em torno de um grande número de questões pontuais, permaneceriam isolados de debates que se dissolveriam sem chegar ganhar força ou visibilidade. Tais 
"ilhas diferenciadas de comunicação" (Dahlgren, 2005, p.152), privilegiariam a diversidade de opiniões entre iguais em vez do afrontamento entre opiniões adversas (Lev-on e Manin, 2006 e 2009). Além disso, nas conversações online pode acontecer de as pessoas falarem sem escutar, de atacarem pessoalmente os participantes em vez de questionarem seus argumentos, de confirmarem em vez de questionarem ideias pré-concebidas e reforçarem convicções em vez de evidenciarem as premissas que sustentam seus pontos de vista diante daqueles que deles discordam (Wright e Street, 2007).

Diante do quadro acima delineado, não se pode partir do princípio de que os espaços conversacionais da internet se estruturam da mesma forma que os espaços públicos ideais habermasianos, privilegiando o entendimento racional entre os participantes na busca da prevalência do melhor argumento, na intenção de se solucionar problemas. Como aponta Chaput (2008), as falas identificadas em fóruns de discussão, por exemplo, nem sempre se apoiam sobre argumentos logicamente válidos e um bom número de opiniões não é acompanhado das justificações necessárias. A tolerância e o respeito diante dos pontos de vista diferenciados - os quais só se concretizam por meio da ação de se colocar no lugar do outro (ideal role taking) - são dificilmente alcançados, dada a predominância da tentativa de convencimento por meio da retórica, da desvalorização e descrédito atribuídos ao ponto de vista alheio, e da tendência ao reforço de opiniões em grupos homogêneos. Além disso, o anonimato reduz a auto-censura dos interlocutores na rede, levando à fraca percepção das normas morais e sociais que dão forma aos atos de fala e às atitudes dos sujeitos. Somado a isso, determinados tipos de moderação colocam em prática formas ilegítimas de censura das mensagens, as quais desrespeitam ou ignoram as regras acordadas para a discussão, restringindo drasticamente a liberdade de expressão dos participantes (Wright, 2009).

Por isso, alguns autores têm salientado que, em vez de partir de um ideal de deliberação e tentar ver como ele se reproduz online, é mais promissor evidenciar como as conversações se definem em espaços virtuais, levando em consideração os estímulos e constrangimentos impostos pela materialidade técnica dos suportes e códigos informáticos; a relação entre as práticas conversacionais online e offline (uma vez que as práticas comunicativas virtuais dos sujeitos não se dissociam de sua inserção em contextos sociais, políticos e culturais definidos); e as formas criativas de apropriação e uso dos suportes técnicos (Graham, 2008; Witschge, 2008). Nesse sentido, os princípios ideais 
definidos por Habermas para caracterizar processos deliberativos face a face podem ser adaptados às trocas online, desde que respeitem a especificidade dos dispositivos e dos tipos de diálogos e vínculos sociais que aí se estabelecem (Stromer-Galley, 2005).

\section{Os critérios normativos para o estudo da deliberação online}

Estudos empíricos das conversações e discussões mediadas por computador têm apresentado propostas metodológicas de análise qualitativa que focalizam elementos originais da dinâmica comunicativa e social das trocas produzidas por participantes de fóruns, chats, listas de discussão e blogs (Monnoyer-Smith, 2007; Marques, 2009, 2010; Stromer-Galley, 2005; Maia, Gomes e Marques, 2011). Trabalhos recentes focalizam, em geral, discussões políticas online e tentam elaborar indicadores capazes de revelar se essas trocas poderiam, e de que modo, trazer contribuições a um processo deliberativo mais amplo (Wilhelm, 2000; Wright e Street, 2007; Vergeer e Hermans, 2008; Maia, 2008; Janssen e Kies, 2005; Sampaio, 2011; Miola, 2011).

Grande parte dessas pesquisas apresenta indicadores analíticos baseados nos princípios normativos formulados por Habermas (1997). Autores como Graham (2008) e Kies (2010) buscam operacionalizar os critérios formais da deliberação, adicionando outros princípios àqueles anteriormente listados, mostrando que eles são úteis, porém limitados para avaliar as comunicações online, pois ignoram as realidades desse tipo de conversação política. Para Graham, os princípios a serem operacionalizados na deliberação online são os seguintes: o processo de entendimento (que envolve o debate crítico racional, a reciprocidade, a reflexividade e a empatia), sinceridade, igualdade discursiva e liberdade discursiva. Ele alerta que não é prudente abandonar critérios norteadores da conversação cotidiana como igualdade, liberdade, reciprocidade e sinceridade, e nem tampouco se pode focar exclusivamente na racionalidade, ignorando os interesses privados dos sujeitos que dialogam online. Kies (2010), por sua vez, emprega em seus estudos a seguinte lista de princípios: inclusão, igualdade discursiva, reciprocidade, justificação, reflexividade, empatia, sinceridade, pluralidade e impacto externo. ${ }^{1}$

Com relação ao impacto externo, Kies (2010) acredita que um processo deliberativo bem-sucedido deve ter influência nas opiniões formadas e nas decisões tomadas fora do contexto de debate. Isso requer que o pesquisador se volte para sinais explícitos de repercussão da discussão analisada na agenda externa, levando em conta também se os participantes da deliberação online integram outros espaços de discussão, criando novos contatos e, assim, desdobrando a rede de trocas comunicativas. 
Outros autores antes de Graham e Kies adaptaram os princípios habermasianos à suas propostas metodológicas de estudo da deliberação online, sobretudo em fóruns de discussão. Schneider (1997), por exemplo, utiliza em sua pesquisa os princípios da igualdade, da diversidade, da reciprocidade e da qualidade. Wilhelm (2000) adota os seguintes princípios: troca de argumentos baseados em razões, reciprocidade, heterogeneidade de pontos de vista, busca e troca de informações. Dahlberg $(2001 ; 2004)$ utiliza os seguintes princípios: tematização e crítica racional de demandas de validade problemáticas, reflexividade, ver os problemas sob o ponto de vista do outro (ideal role taking), sinceridade, inclusão e igualdade discursiva, autonomia com relação ao Estado e ao poder econômico. Já para Stromer-Galley (2005), existem oito “ingredientes" essenciais para a discussão política online: expressão da opinião fundada em razões, referências a fontes externas, ausência de agressão, choque de perspectivas (desacordo deliberativo), níveis iguais de participação, coerência, reflexividade, interatividade e narratividade.

De modo a revelar como os princípios deliberativos podem ser operacionalizados para mapear a deliberação online, retomamos aqui os princípios utilizados por autores que consideram pertinente partir dos parâmetros indicados por Habermas, cuidando para não prefigurar tais princípios de modo a torná-los imunes a uma não-confirmação empírica. Afinal, os princípios guiam uma proposta metodológica sem engessá-la, o que permite aos pesquisadores refutar alguns deles ou constatar sua inexistência. Na seção que se segue, apresentarei uma proposta metodológica que sintetiza as principais caracterísitcas das abordagens feitas por Stromer-Galley (2005), Graham (2008) e Kies (2010), por considerar que seus desenhos metodológicos são aqueles que mais se aproximam de uma compreensão da deliberação online como processo social, político e comunicativo que se define para além dos procedimentos e princípios discursivos, focalizando uma análise qualitativa da construção discursiva do problema em pauta, as relações estabelecidas entre os diferentes interlocutores e as especificidades dos dispositivos técnicos.

\section{Uma proposta de operacionalização da deliberação online}

Acredito que pesquisadores interessados em investigar qualitativamente o processo deliberativo online podem organizar seus desenhos metodoló- 
gicos de pesquisa a partir de uma tentativa de caracterizar duas das faces das interações comunicativas online: a) a face afetiva e sociável; e b) a face marcada pela discussão focalizada e motivada pela busca do entendimento e da negociação.

\section{A) A dimensão afetivo-política das conversações online}

A internet apresenta atualmente alguns contextos nos quais os cidadãos comuns podem expressar suas histórias pessoais e seus pontos de vista sobre determinadas questões, estabelecendo diálogos e trocas motivados tanto por fatores afetivos quanto políticos. Reconhecer e/ou construir um lugar comum na internet significa selecionar, por afinidade, não só um espaço de interação, mas um tema específico e parceiros determinados. Nesse sentido, acompanhar as pessoas comuns em interações online nos ajuda a identificar algumas marcas na construção de mensagens e de linguagens que expressam como os laços sociais são estabelecidos (Bretas, 2008). Acredito que, nessas interações, elementos que a princípio estão ligados aos afetos e ao desejo de estabelecer vínculos efêmeros podem dar a ver tipos de interações mais argumentativas, ou seja, preocupadas em identificar e melhor compreender problemas que, a partir da explicitação e expressão de interesses particulares, remetam a temas de interesse público. Tal aproximação entre vínculos de ordem afetiva e política é mais perceptível quando avaliamos o modo como os interlocutores definem e interpretam coletivamente, em seus próprios termos, seus dilemas, desejos e necessidades de modo a chegar a uma percepção mais objetiva e generalizada de sua situação.

De modo geral, as pessoas tendem a participar de discussões online em fóruns não destinados ao debate de temas políticos, mas sim de hobbies, interesses e atividades partilhadas. Para Wojcieszak e Mutz (2009), tópicos políticos controversos podem surgir nessas discussões, nos oferecendo a oportunidade de acompanhar a tematização de questões ligadas ao âmbito político e ao interesse coletivo, expondo os participantes a perspectivas diferentes (casual political talk on line).

Para mostrar como vínculos afetivos e políticos de sociabilidade podem ser estabelecidos por meio de conversações informais na internet, o pesquisador deve privilegiar a análise das relações discursivas entre os participantes (e não os indivíduos como unidades de análise). Nesse sentido, uma metodologia de enfoque qualitativo pode partir da seleção de sequências 
ou fios de discussão ${ }^{2}$ que se revelem capazes de evidenciar como vínculos afetivos de sociabilidade (de identificação e empatia) podem se entrecruzar com vínculos políticos (ou politizados) ao longo das conversações informais realizadas no contexto de um espaço online de debate (fórum, chat, lista de discussão, orkut, twitter etc). Com o objetivo de melhor caracterizar essas sequências, estabeleci três categorias não-exaustivas de análise que, partindo da ideia de combinação entre aspectos afetivos e argumentativos, pudessem criar aberturas (via conversação) para a emergência de discordâncias e confrontos de pontos de vista nas trocas comunicativas online. São elas:

a) Modelagem mútua de um quadro de sentidos compartilhados (definição do contexto e das regras da interação). No início de uma discussão coletiva online, é possível capturar elementos que evidenciam o empenho dos participantes em criar um ambiente no qual a seleção de temas e a identificação se dão por afinidade. Por meio da conversação inicialmente estabelecida, é possível perceber também que eles tentam modelar um contexto, ou um pano de fundo comum para a discussão, a partir da mobilização de referências partilhadas e da elaboração de enquadramentos interpretativos acerca do tópico inicial de debate. Essa conversação inicial serve à construção cooperativa de informações e à definição de um conhecimento comum para orientar os participantes em suas trocas (Habermas, 1997).

De modo geral, é possível afirmar que, ao primeiro contato entre os participantes de uma discussão online, caracterizado pelo reconhecimento dos parceiros de interação e pelas tentativas de modelagem de um campo comum de referências, somam-se as tentativas de compreender as diferentes dimensões da questão em pauta. Sob esse aspecto, um problema de interesse geral é fruto não só de uma indicação de tópico para o debate coletivo, mas também de uma atividade processual que envolve a identificação de atores, a configurações de ações, a avaliação dos pontos de vista e a formulação dos parâmetros que definem o contexto e as regras da interação. No processo de conversação, a modelagem mútua de um quadro de sentidos compartilhados pode revelar como os interlocutores constroem, misturando aspectos emocionais e racionais, uma compreensão acerca de sua situação e dos modos de lidar com ela.

Os fios de discussão (ou threads) designam as diferentes discussões que se desdobram em um mesmo fórum ou espaço virtual de conversação, sendo que cada uma foi iniciada quando um participante posta uma mensagem inicial. Todo fio de discussão deve ter uma forte coerência temática (Marcoccia, 2003). 
b) Tensões entre o jogo lúdico da interação afetiva e o aparecimento de discordâncias. Se nos primeiros momentos de interação em um espaço de conversação online há uma tendência de se verificar a explicitação de referências, ideias, hábitos e experiências comuns entre os participantes, em um segundo momento, o compartilhamento pode dar lugar à discordância. Quando isso ocorre, é possível ver como o fluxo descontínuo e disperso da troca comunicativa sociável se converte em um movimento voltado para a tomada de posições e para o início de uma negociação de argumentos que devem ser justificados diante dos outros. Ao explicitarem seus pontos de vista particulares, os interlocutores tendem a justificá-los ou mesmo a evidenciar as premissas que os sustentam. Nesse processo, consideram a perspectiva apresentada pelos outros e, eventualmente, alteram seu posicionamento.

c) Modos de estabelecer contato com o outro: narrativas, empatia e marcação das diferenças. A empatia entre participantes de conversações online é estabelecida, não raro, por meio de narrativas e testemunhos que servem, ao mesmo tempo, como forma de criar vínculos de identificação com os demais participantes (a ação de colocar-se no lugar do outro e perceber um problema a partir da perspectiva alheia) e como uma razão ou evidência fornecida ao debate (Stromer-Galley, 2005). Sob esse viés, o testemunho pode ser visto como um procedimento prático empregado pelos indivíduos para tornar seus pontos de vista mais inteligíveis e passíveis de serem aceitos como válidos. Ao assumir uma forma narrativa, o testemunho retira as experiências do locus de sua ocorrência particular e lhe confere um valor público de ilustração, exemplo, prova ou argumento (Young, 2000).

O processo dialógico de reunião de fatos, testemunhos, informações e histórias pessoais expõe os participantes de discussões online a várias ideias e facilita a descoberta e a compreensão de pontos comuns e das divergências existentes entre eles. Ao expressarem testemunhos e narrativizarem experiências, os interlocutores repensam aspectos de suas identidades e tomam consciência de padrões "implícitos" de julgamento do valor moral dos sujeitos.

A análise empírica da conversação informal online necessita de uma metodologia qualitativa capaz de considerar não só as trocas fundadas em argumentos crítico-racionais, mas também as trocas que mobilizam afetos, expressões emocionais e que privilegiam um uso dos dispositivos técnicos capaz de produzir uma aproximação entre pontos de vista mais subjetivos (ligados a percepções particulares do bem-viver) e razões que tentam mobilizar experiências coletivas. 
Nesse sentido, a riqueza dos modos de comunicação presentes em espaços conversacionais online pode ser melhor apreendida por uma metodologia que contemple e articule: i) a negociação de um pano de fundo compartilhado e diante do qual se definem posicionamentos; ii) a estrutura argumentativa das trocas; iii) as interseções entre diferentes formas de comunicação utilizadas e permitidas pela materialidade técnica, como as demandas racionais de validade de um argumento e as formas estético-expressivas (agressividade, humor, retórica, sinais visuais de assentimento ou repreensão, testemunho, uso de imagens, etc.), de modo a construir diálogos que permitam a expressão das diferenças e a reflexão sobre aspectos da identidade e da alteridade.

A Tabela 2 sintetiza as principais características das variáveis analíticas aqui apresentadas para o estudo das conversações em espaços de discussão online.

Tabela 2 - Dimensões afetivas e políticas das conversações online

\begin{tabular}{c|c|c}
\hline $\begin{array}{c}\text { Aspectos afetivos da } \\
\text { interação online }\end{array}$ & $\begin{array}{c}\text { As contribuições da conversação } \\
\text { informal para a explicitação de tópicos } \\
\text { de natureza política }\end{array}$ & Variáveis analíticas \\
\hline $\begin{array}{c}\text { Busca de afinidades } \\
\text { eletivas e referências } \\
\text { partilhadas. }\end{array}$ & $\begin{array}{c}\text { Busca, na experiência subjetiva dos participantes, } \\
\text { por fatos e pontos de vista que podem ser úteis } \\
\text { na interpretação cooperativa e conflitiva de uma } \\
\text { questão ou problema; }\end{array}$ & $\begin{array}{c}\text { Modelagem mútua de de um } \\
\text { quadro de sentidos comparti- } \\
\text { Ihados (definição do contexto } \\
\text { e das regras da interação). }\end{array}$ \\
\hline $\begin{array}{c}\text { Curiosidade em descobrir 0 } \\
\text { que o outro pensa e como posiciona diante de } \\
\text { determinadas questões. }\end{array}$ & $\begin{array}{c}\text { Apropriação e contestação crítica dos pontos } \\
\text { de vista publicamente disponíveis. } \\
\text { Negociação de interpretações sobre a situação } \\
\text { em causa: confronto de pontos de vista. }\end{array}$ & $\begin{array}{c}\text { Tensões entre o jogo } \\
\text { lúdico da interação afetiva } \\
\text { e o aparecimento } \\
\text { de discordâncias. }\end{array}$ \\
\hline $\begin{array}{c}\text { Dividir experiências, } \\
\text { valores, hábitos e idéias. }\end{array}$ & $\begin{array}{c}\text { Articulação da experiência pessoal } \\
\text { com princípios mais gerais; } \\
\text { sobre a emoçãa e sobre formas de comunicação } \\
\text { como o testemunho (storytelling). }\end{array}$ & $\begin{array}{c}\text { Modos de estabelecer } \\
\text { contato com o outro: } \\
\text { narrativas, empatia e } \\
\text { marcação das diferenças }\end{array}$ \\
\hline
\end{tabular}

Fonte: elaborada pela autora.

\section{B) A dimensão da discussão política e deliberativa}

Essa parte da metodologia qualitativa de estudo da discussão política online pode ser feita por meio da operacionalização de cinco princípios deliberativos principais: 


\section{1) Discussão crítico-racional}

Esse critério nos permite ver os modos como os participantes de trocas comunicativas em espaços online expressam seus pontos de vista sob a forma de argumentos potencialmente aceitáveis por todos e capazes de ser desafiados e justificados. Kies (2010) afirma que o processo de justificação deve ser racional e acessível para que os interlocutores compreendam as razões que se encontram por trás dos argumentos sustentados por seus parceiros de debate. Para Stromer-Galley (2005), um argumento é racional se a afirmação feita promove evidências que podem ser observadas e confirmadas (apelando para uma base normativa compartilhada), ou negadas empiricamente. Essa autora chama a atenção para a importância do desacordo no processo de justificação das opiniões. O desacordo se manifesta quando há um problema que requer que os parceiros discursivos se orientem para o entendimento recíproco. $\mathrm{O}$ desacordo, ao indicar a presença de visões opostas acerca de um problema (heterogeneidade de perspectivas), torna-se importante porque: a) revela o embate entre perspectivas que não convergem (dissolução de enclaves e da polarização em torno de uma só opinião); b) oferece perspectivas alternativas sobre o problema; c) descentra opiniões cristalizadas.

Graham (2008) afirma ainda que a discussão crítico-racional online deve ter coerência e continuidade. A coerência é alcançada quando os participantes seguem um tópico de discussão até que um entendimento mútuo, ainda que provisório, seja alcançado. E a continuidade revela o nível de extensão do debate em cada fio de discussão identificado.

\section{Operacionalização}

A discussão crítico racional é baseada no oferecimento de afirmações e respostas baseadas em razões, ou seja, acompanhadas de justificativas. Uma análise de conteúdo de todas as mensagens compreendidas pelo corpus empírico faz-se necessária (localizado temporal e espacialmente - por exemplo, um determinado fórum de discussão, cujas discussões foram capturadas em um período específico). Esta análise tem por objetivo observar se as afirmações e respostas dos participantes são baseadas em razões (apresentam justificativas), se elas se articulam sob a forma de uma cadeia de enunciados (turnos de fala entre afirmações e respostas) e o quão complexas elas são (Graham, 2008; Kies, 2010). É preciso definir também que tipo de evidências fundamentam as razões apresentadas: fato concreto, comparação, exemplo (real, ficcional 
ou hipotético), experiência pessoal ou histórias de outras fontes que podem ser verificadas (jornais, sites, artigos, citações, livros ou experts). É importante chamar a atenção para as evidências baseadas na experiência pessoal. De acordo com Stromer-Galley (2005), os indivíduos envolvidos em um processo deliberativo não oferecem a seus parceiros somente argumentos racionais, mas também narrativas e testemunhos que podem valer como justificativas que auxiliam na correção de pré-entendimentos e preconceitos. Testemunhos servem, ao mesmo tempo, como forma de criar vínculos de identificação e empatia com outros participantes (a ação de colocar-se no lugar do outro e perceber um problema a partir da perspectiva alheia) e como uma razão ou evidência fornecida ao debate (Maia, 2008). Uma análise de conteúdo das mensagens postadas pode nos indicar como o uso da narrativa e do testemunho promove ou não empatia.

O desacordo pode ser avaliado a partir da identificação de refutações e opiniões contrárias, as quais também sugerem a presença de uma reflexão crítica, uma vez que não só incluem afirmações que indicam discordância, mas também promovem razões para apoiar essas afirmações, indicando a existência de uma reflexão prévia. A coerência pode ser avaliada a partir do momento em que o pesquisador ordena, em fios de discussão, as mensagens postadas. Quanto maior a extensão do debate em cada fio de discussão, ou seja, quanto mais os participantes exploram e esgotam um tema, maior tende a ser a coerência e a continuidade do embate (Graham, 2008).

\section{2) Reciprocidade}

Para Stromer-Galley (2005), o que torna uma opinião deliberativa não é somente o fato de ela ser construída por meio de uma cuidadosa consideração, de evidências e argumentos de apoio, mas o fato de ela ter sido confrontada pela visão oposta dos outros. Por isso, a reciprocidade envolve respeito mútuo e uma escuta atenta do ponto de vista apresentado pelos outros. Ela nos revela em que medida os participantes trocam opiniões, pedem esclarecimentos, incorporam e/ou respondem aos pontos de vista de seus interlocutores.

\section{Operacionalização}

Realizar uma análise qualitativa que associe a reciprocidade à alternância de turnos de fala entre os participantes. Verificar se os participantes 
respondem somente a um interlocutor (centralização), pois uma estrutura centralizada de respostas pode implicar baixo nível de reciprocidade (Graham, 2008). Notar também se os participantes estão se engajando uns com os outros ou se estão simplesmente se dedicando a monólogos nos quais os parceiros não respondem. Um processo recíproco implica troca de turnos e respostas às afirmações dos outros (quem responde a quem) (Stromer-Galley, 2005). Quando há a proeminência de um único participante, os participantes deixam de escutar e responder uns aos outros e passam a responder somente a um outro. Segundo Kies (2010), a análise qualitativa da reciprocidade deve avaliar em que medida uma mensagem leva em consideração argumentos e opiniões de uma mensagem precedente.

\section{3) Reflexividade}

Uma das principais características do processo deliberativo é que os participantes se mantenham flexíveis para alterar suas opiniões e preferências quando confrontados com críticas ou com argumentos sustentados pelos outros, demonstrando interesse em considerar e entender perspectivas distintas.

\section{Operacionalização}

Stromer-Galley (2005) afirma que essa variável parece ser melhor medida por meio de entrevistas com os participantes em vez da observação de sua troca discursiva. Isso porque a reflexividade envolve a revisão individual (e geralmente interna) de um ponto de vista à luz das considerações dos outros. Entretanto, Graham (2008, p. 29) aposta na análise de conteúdo que seleciona os exemplos e evidências acionados para justificar um argumento. Para ele, utilizar evidências para sustentar um argumento ou desafiar outros indica que o participante teve tempo de conhecer, avaliar, refletir e de contrapor a visão oposta à sua. Kies (2010) defende uma operacionalização que combina análise de conteúdo (para identificar mudanças de opinião) e entrevistas com os participantes, para saber se eles mudaram suas opiniões ou se demonstram estar mais informados depois do debate.

\section{4) Igualdade discursiva}

Os participantes devem ter igual oportunidade de introduzir e questionar afirmações, além de expressar necessidades e desejos. Todo participante 
precisa ter condições de participar em pé de igualdade com os demais. Ninguém deve dominar a conversação ou silenciar os outros.

\section{Operacionalização}

Graham (2008) sugere uma análise que tente perceber a distribuição de vozes ao longo dos fios de discussão identificados pelo pesquisador. Segundo ele, em uma vertente mais quantitativa, é importante ver se há equilíbrio entre a quantidade de mensagens de cada participante. Isso pode revelar quem está sendo considerado, se algum participante ou tópico de discussão ganhou maior destaque, se há participantes mais "populares" do que outros (Kies, 2010). Sob esse aspecto, as sugestões de Graham se aproximam daquelas feitas por Stromer-Galley (2005), que aponta para a necessidade de se identificar o número de pessoas que participam das discussões e a frequência de sua participação. Esse tipo de mensuração permitiria ver se há dominância de uns sobre os outros. Além disso, Graham considera extremamente relevante observar se há ameaças às condições de igualdade, ou seja, se existem mensagens que degradam ou negligenciam um participante e/ou os argumentos por ele apresentados. Ataques pessoais, isto é, mensagens que ofendem um participante em vez de questionar suas opiniões, indicam que o diálogo não atende também aos requisitos da reciprocidade, da reflexividade e da discussão crítico-racional. Como destaca Stromer-Galley, frases agressivas não enaltecem o compromisso com a consideração recíproca.

\section{5) Liberdade discursiva}

Os participantes não podem ter suas opiniões e afirmações suprimidas e restringidas. Impedir a livre expressão de opiniões demonstra o desrespeito à paridade participativa. Geralmente, a liberdade discursiva pode ser tanto promovida quanto ameaçada pela arquitetura, pelas formas de mediação das trocas e também pelo modo como as regras de conversação são estabelecidas e fixadas nos espaços online de diálogo. Por exemplo, a mediação ou falta dela pode influenciar a liberdade discursiva dos participantes. Um fórum não moderado permite escolher os temas a serem debatidos e faz com que os participantes sejam responsáveis pela agenda e pela observância das regras da discussão (Wright e Street, 2007). A atribuição de papéis entre os participantes (moderador, contribuinte, editor, etc.) gera privilégios e de- 
veres que desequilibram a paridade de status dos participantes. Contudo, as restrições nem sempre prejudicam a deliberação, podendo até estimulá-la. Nesse sentido, é importante perceber como os aspectos formais determinados pelos dispositivos técnicos constrangem as manifestações e interações dos participantes (Wright, 2009). Como observa Marcoccia (2003), o dispositivo técnico possui uma dupla função: ao mesmo tempo em que é um quadro que define os sujeitos participantes, ele é também instrumento que torna possível a discussão. Mas os contrangimentos impostos são vários. O tema ou título de um fórum de discussão, por exemplo, circunscreve o domínio de interesse definindo as mensagens que serão acolhidas e excluindo outras. Quando redigimos uma mensagem online, nossa escrita deve corresponder a um formato muito específico: deve ser respeitado o espaço da janela dentro da qual a mensagem será formatada; ao responder a alguém, tudo fica mais difícil se não há um mecanismo de citação que recupere as mensagens que desejamos comentar, o que também impede a percepção da sequencialidade dos fios de discussão e da alternância dos turnos de fala. Certamente, o design da interface prescreve certos comportamentos comunicacionais esperados, mas as práticas dos interagentes sempre contam com usos imprevistos que subvertem algumas dessas configurações.

\section{Operacionalização}

Segundo Graham (2008), é importante mapear as principais características do dispositivo técnico e do design da interface, procurando apontar sobretudo os códigos e normas que definem, por exemplo, a proibição ou não de linguagens agressivas e abusivas, a presença da moderação, reclamações de participantes sobre edições e remoções de suas mensagens, a existência de modos de censura que os participantes estabelecem entre si (impedindo os outros de se posicionar ou forçando-os ao silêncio e/ou abandono da discussão).

As tabelas 3 e 4 sintetizam, respectivamente, a proposta de configuração de uma metodologia de análise do processo comunicativo de deliberação online e os principais aspectos políticos e normativos envolvidos em tal processo. 
Tabela 3 - Síntese dos operadores analíticos deliberativos

\begin{tabular}{|c|c|}
\hline Princípios & Operacionalização \\
\hline $\begin{array}{l}\text { Discussão crítico- } \\
\text {-racional }\end{array}$ & $\begin{array}{l}\text { Fazer uma análise de conteúdo de todas as mensagens: mapear afirmações e respostas } \\
\text { acompanhadas de justificativas; definir as evidências e fontes que fundamentam as } \\
\text { razões apresentadas (incluir também o uso da narrativa e do testemunho). } 0 \text { desacordo } \\
\text { pode ser avaliado a partir da identificação de refutações e opiniões contrárias. } \\
\text { A coerência e a continuidade podem ser avaliadas a partir do momento em que o } \\
\text { pesquisador ordena, em fios de discussão, as mensagens postadas. }\end{array}$ \\
\hline Reciprocidade & $\begin{array}{l}\text { Ver a alternância de turnos de fala entre os participantes (quem responde a quem: } \\
\text { os participantes respondem somente a um interlocutor? em que medida uma mensa- } \\
\text { gem leva em consideração argumentos e opiniões de uma mensagem precedente? No- } \\
\text { tar se os participantes estão se engajando uns com os outros ou se estão simplesmente } \\
\text { se dedicando a monólogos nos quais os parceiros não respondem } \\
\text { (indicada a análise de conteúdo). }\end{array}$ \\
\hline Reflexividade & $\begin{array}{l}\text { Verificar se os participantes utilizam evidências para sustentar um argumento } \\
\text { ou desafiar outros, o que indica que tiveram tempo de conhecer, avaliar, refletir } \\
\text { e de contrapor a visão oposta à sua. Os participantes demonstram interesse em } \\
\text { considerar e entender outras perspectivas (análise de conteúdo). Para saber se } \\
\text { os participantes mudaram de opinião ou revisaram seus argumentos à luz do } \\
\text { que foi dito no debate é indicada a realização de entrevistas. }\end{array}$ \\
\hline Igualdade discursiva & $\begin{array}{c}\text { Verificar se há equilibrio entre a quantidade de mensagens de cada participante. Obser- } \\
\text { var se existem mensagens que degradam ou negligenciam um participante } \\
\text { e/ou os argumentos por ele apresentados. Verificar se os participantes } \\
\text { trocam razões e oferecem evidências baseadas em narrativas pessoais, } \\
\text { que se constituem como modo de comunicação e busca do } \\
\text { entendimento alternativo à racionalidade. }\end{array}$ \\
\hline Liberdade discursiva & $\begin{array}{c}\text { Perceber e verificar se os dispositivos técnicos, a arquitetura discursiva dos } \\
\text { espaços online e/ou a presença de um moderador constrangem as manifestações } \\
\text { e interações dos participantes. Existem arquiteturas discursivas mais favoráveis } \\
\text { ao debate e outras menos favoráveis. }\end{array}$ \\
\hline
\end{tabular}

Fonte: elaborada pela autora. 
Tabela 4 - Aspectos políticos e princípios normativos englobados pela deliberação online

\begin{tabular}{|c|c|c|}
\hline $\begin{array}{l}\text { Aspectos políticos } \\
\text { da interação online }\end{array}$ & $\begin{array}{l}\text { Princípios norma- } \\
\text { tivos envolvidos }\end{array}$ & 0 que observar nas ações comunicativas online \\
\hline $\begin{array}{l}\text { Tentativas de definição } \\
\text { e compreensão da } \\
\text { questão em causa. }\end{array}$ & $\begin{array}{l}\text { Discussão } \\
\text { crítico-racional } \\
\text { (viés da inclusão } \\
\text { e publicização de } \\
\text { entendimentos } \\
\quad \text { plurais) }\end{array}$ & $\begin{array}{l}\text { Identificar uma série de possibilidades de abordar } \\
\text { o problema. Procurar compreender as principais } \\
\text { nuances de uma questão. Estabelecer o que é } \\
\text { importante para os parceiros de interação. } \\
\text { Apropriação e contestação crítica dos pontos } \\
\text { de vista publicamente disponíveis. }\end{array}$ \\
\hline $\begin{array}{l}\text { Negociação e dissenso } \\
\text { de interpretações sobre } \\
\text { a situação em causa: } \\
\text { confronto de pontos } \\
\text { de vista. }\end{array}$ & $\begin{array}{l}\text { Discussão } \\
\text { crítico-racional, } \\
\text { reciprocidade, } \\
\text { reflexividade, } \\
\text { liberdade } \\
\text { participativa }\end{array}$ & $\begin{array}{l}\text { Identificar o desacordo e os argumentos em oposição. } \\
\text { Justificar posições, oferecer razões embasadas por evidências. } \\
\text { Conhecer a opinião oposta (compreender ainda que não haja } \\
\text { concordância). Explicitação das premissas que sustentam } \\
\text { pontos de vista. Disposição em alterar opiniões } \\
\text { e preferências. Livre expressão e paridade. }\end{array}$ \\
\hline $\begin{array}{l}\text { Ampliar os horizontes } \\
\text { de entendimento para } \\
\text { além do ponto de vista } \\
\text { subjetivo. Compreender } \\
\text { a perspectiva alheia. }\end{array}$ & $\begin{array}{l}\text { Igualdade } \\
\text { discursiva }\end{array}$ & $\begin{array}{l}\text { Ausência ou presença de dominância, de formas de degra- } \\
\text { dação de participantes e/ou de seus argumentos; empatia, } \\
\text { evidências vindas da experiência pessoal, colocar-se no lugar } \\
\text { do outro. Dialogar para além das diferenças. Articulação da } \\
\text { experiência pessoal com princípios mais gerais. }\end{array}$ \\
\hline
\end{tabular}

Fonte: elaborada pela autora.

\section{Considerações finais}

O modelo habermasiano de esfera pública e os princípios normativos que definem uma situação deliberativa estão na base de um conjunto de trabalhos a respeito da discussão política online. Ao recuperar um conjunto representativo de autores interessados em construir uma abordagem qualitativa dos processos deliberativos online, afirmo que não se deve transpor e aplicar cruamente esse modelo teórico ideal para o estudo das trocas políticas mediadas por computador. A melhor alternativa é partir de tal modelo para estabelecer categorias de análise e alguns parâmetros definidores das ações comunicativas delineadas pelos parceiros de interação online quando se deparam com o dissenso (Chaput, 2008; Wojcieszak e Mutz, 2009; Marques, 2010). O viés metodológico aqui explorado evidencia como princípios normativos podem ser operacionalizados de modo a construir uma abordagem que considere a natureza e a organização dinâmica das trocas comunicativas online, os vínculos de sociabilidade entre 
os parceiros e as características dos dispositivos técnicos. O estudo do engajamento discursivo na rede não pode ser reduzido unicamente à investigação da troca argumentativa. É preciso sobretudo observar as situações e os contextos nos quais essa troca se produz, assim como a construção, por meio do debate, das regras às quais os interlocutores se submetem.

\section{Referências bibliográficas}

BOHMAN, James. 2004. "Expanding dialogue: the internet, the public sphere and prospects for transnational democracy”. Sociological Review, v. 52, p. 131-155.

BRETAS, Maria Beatriz A. 2008. "Pessoas comuns no ciberespaço: dimensões éticas e estéticas da ocupação midiática". Trabalho apresentado no GT Comunicação e Sociabilidade no XVII Encontro da Compós. UNIP-SP, 3 a 6 de junho.

CHAPUT, Mathieu. 2008. "Analyser la discussion politique en ligne: de l’idéal délibératif à la reconstruction des pratiques argumentatives". Réseaux, n. 150 , p. 83-106.

DAHLBERG, Lincoln. 2001. "The internet and democratic discourse: exploring the prospects of online deliberative forums extending the public sphere". Information, Communication \& Society, v. 4, n. 4, p. 615-633. . 2004. "Net-public sphere research: beyond the first phase". Javnost-The Public, v. 11, n. 1, p. 27-44.

DAHLGREN, Peter. 2005. "The internet, public spheres, and political communication: dispersion and deliberation". Political Communication, n. 22, p. 147-162.

DEAN, Jodi. 2003. "Why the net is not a public sphere". Constellations, v. 10, n. 1, p. 95-112.

DOURY, Marianne \& MARCOCCIA, Michel. 2007. "Forum Internet et courrier des lecteurs: l'expression publique des opinions". Hermès, v. 47, p. 41-50.

GRAHAM, Todd. 2008. "Needles in a haystack: a new approach for identifying and assessing political talk in non-political discussion forums". Javnost-The Public, v. 15, n. 2, p. 17-36.

HABERMAS, Jürgen. 1997. Direito e democracia: entre facticidade e validade. Vol II. Tradução de Flávio Beno Siebeneichler. Rio de Janeiro: Tempo Brasileiro. 
. 2005. "Concluding comments on empirical approaches to deliberative politics". Acta Politica, v. 40, p. 384-392.

2006. "Political communication in media society: does democracy still enjoy an epistemic dimension? the impact of normative theory on empirical research". Communication Theory, v. 16, p. 411-426.

JANSSEN, Davy \& KIES, Raphaël 2005. "Online forums and deliberative democracy: hypotheses, variables and methodologies". Acta Política, v. 40, p. 317-335.

KIES, Raphaël. 2010. Promises and limits of web-deliberation. New York: Palgrave Macmillan.

LEV-ON Azi \& MANIN, Bernard. 2006. "Internet: la main invisible de la deliberation". Esprit, n. 5, p. 195-212.

. 2009. "Happy accidents: deliberation and online exposure to opposing views". In: DAVIES, Todd \& GANGADHARAN, Seeta (eds.). Online deliberation: design, research, and practice. California: CSLI Publications.

MAIA, Rousiley. 2008. "Democracia e a internet como esfera pública virtual: aproximação às condições da deliberação”. In: GOMES, Wilson \& MAIA, Rousiley (orgs.). Comunicação e democracia: problemas e perspectivas. São Paulo: Paulus.

; GOMES, Wilson \& MARQUES, Francisco P. Jamil (orgs.). 2011. Internet e participação política no Brasil. 1 ed. Porto Alegre: Sulina.

MARCOCCIA, Michel. 2003. "Parler politique dans un forum de discussion". Langage \& Société, n. 104, p. 9-55.

MARQUES, Angela Cristina S. 2009. "La conversation civique sur internet: contributions au processus délibératif”. Estudos em Comunicação/Études en Communication, v. 5, p. 21-52.

.2010. "A conversação informal na internet: condições interacionais e contribuições para uma análise qualitativa”. In: BRAGA, José Luiz; LOPES, Maria Immacolata V. \& MARTINO, Luiz Cláudio (orgs.). Pesquisa empírica em comunicação. São Paulo: Paulus.

MIOLA, Edna. 2011. "Iniciativas institucionais de deliberação inline: um estudo do fórum de discussão do portal da Câmra dos Deputados". In: MAIA, Rousiley; GOMES, Wilson \& MARQUES, Francisco P. Jamil (orgs.). Internet e participação política no Brasil. $1^{\text {a }}$ ed. Porto Alegre: Sulina. 
MONNOYER-SMITH, Laurence. 2007. "Le débat public en ligne: une ouverture des espaces et des acteurs de la deliberation". Texto apresentado no Congresso da Association Française de Sciences Politiques. Toulouse, 5 a 7 de setembro.

MOUFFE, Chantal. 1999. "Deliberative democracy or agonistic pluralism?”. Social Research, v. 66, n. 3, p.745-758.

PAPACHARISSI, Zizi. 2002. "The virtual sphere: the internet as a public sphere”. New Media \& Society, v. 4, n. 1, p. 9-27.

SAMPAIO, Rafael C. 2011. "Quão deliberativas são discussões na rede? Um modelo de apreensão da deliberação online”. In: MAIA, Rousiley; GOMES, Wilson; MARQUES, Francisco P. Jami. (orgs.). Internet e participação política no Brasil. $1^{\text {a }}$ ed. Porto Alegre: Sulina.

SCHNEIDER, Steven. 1997. Expanding the public sphere through computer-mediated communication: political discussion about abortion in a usenet newsgroup. Tese de PhD. Massachusetts: Massachusetts Institute of Technology/MIT Political Science.

STROMER-GALLEY, Jennifer. 2005. "Decoding deliberation online”. Trabalho apresentado na Second Conference on Online Deliberation. Palo Alto, California, 20 a 22 de maio.

VERGEER, Maurice \& HERMANS, Liesbeth. 2008. "Analyzing online political discussions: methodological considerations". Javnost-the public, v. 15, n. 2, p. 37-56.

WILHELM, Anthony. 2000. Democracy in the digital age: challenges to political life in cyberspace. London: Routledge.

WITSCHGE, Tamara. 2004. "Online deliberation: possibilities of the internet for deliberative democracy”. In: SHANE, Peter (ed.). Democracy online: the prospects for political renewal through the Internet. New York: Routledge. 2008. "Examining online public discourse in context: a mixed method approach". Javnost-the public, v. 15, n. 2, p.75-92.

WOJCIESZAK, Magdalena \& MUTZ, Diana. 2009. "Online groups and political discourse: do online discussion spaces facilitate exposure to political disagreement?". Journal of Communication, v. 59, p. 40-56.

WRIGHT, Scott \& STREET, John. 2007. "Democracy, deliberation and design: the case of online discussion forums". New Media \& Society, v. 9 , n. 5 , p. $849-869$. 
WRIGHT, Scott. 2009. "The role of the moderator: problems and possibilities for government-run online discussion forums". In: DAVIES, Todd \& GANGADHARAN, Seeta (eds.). Online deliberation: design, research, and practice. California: CSLI Publications.

YOUNG, Iris. 2000. Inclusion and democracy. Oxford: Oxford University Press.

\section{Resumo}

Estudos empíricos das conversações e discussões mediadas por computador têm apresentado propostas metodológicas de análise qualitativa que focalizam elementos originais da dinâmica comunicativa e social dessas trocas. Trabalhos recentes focalizam discussões políticas online e apresentam indicadores capazes de revelar como essas trocas poderiam contribuir para um processo deliberativo mais amplo acerca de questões específicas. Apresento alguns modelos metodológicos de análise qualitativa de processos de deliberação online e, a partir de uma síntese de suas principais características, argumento que essa análise não pode ser reduzida unicamente à investigação da troca argumentativa. É preciso, sobretudo, observar as situações e os contextos de sociabilidade nos quais as interações se produzem, assim como a construção e negociação das regras às quais os interlocutores se submetem.

Palavras-chave: deliberação online; metodologia qualitativa; sociabilidade; conversação política; comunicação mediada por computador (CMC).

\section{Abstract}

Empirical studies of computer mediated conversations and debates have presented methodological proposals of qualitative analysis that focus on the original elements of communicative and social dynamics of these exchanges. Recent works have investigated how online political deliberation can be analyzed presenting multiple variables capable of showing how these exchanges could contribute to widen deliberative processes concerning specific questions. I present some methodological models of qualitative analysis of online deliberation processes by making a synthesis of their main characteristics. I argue that this analysis cannot be reduced to the inquiry on the argumentative exchange. It is necessary to observe the situations and the contexts of sociability in which the interactions take place as well as the construction and negotiation of the rules that will govern interlocutors' interactions.

Key words: online deliberation; qualitative methodology; sociability; political conversation; computer mediated communication (CMC).

Recebido em março de 2011. Aprovado em junho de 2011. 